\title{
A Method for Rockfall Hazard Assessments — Chapmans Peak Drive, Cape Town, South Africa
}

\author{
P. Schlotfeldt Golder Associates Ltd, Canada
}

\begin{abstract}
GIS was used as one of the primary analysis tools during a rockfall hazard assessment and analyses of Chapmans Peak Drive, south of Cape Town. This paper describes the methodology used and the results of this work. Key methods used included 1) the development of a digital elevation model (DEM) used to delineate rockfall runout zones; 2) rating zones using an adapted version of the Oregon rockfall hazard rating system (RHRS) in order to determine the relative vulnerability of individual zones to rockfall; 3) undertaking rock trajectory analyses to determine the distribution of kinetic energy for identified rockfall runout zones; and 4) undertaking event tree analyses based on the synthesis of all data in order to establish zones with the highest risk of fatalities. The results of this work shows that the vulnerability and risk varies considerably between zones. The reasons for these differences are briefly elucidated.
\end{abstract}

\section{Introduction}

Chapmans Peak Drive, located between Hout Bay and Noordhoek, on the Atlantic ocean side of the Cape Peninsula, near Cape Town, South Africa (Figure 1) is a favourite tourist route and is famous for its scenic beauty. The Drive, parts of which hug the near vertical mountainside of Chapmans Peak, is both a major tourist attraction and an important transportation link between the southern part of the Cape Peninsula and the city of Cape Town. At least ten people have been killed and many more injured as a result of rockfalls along parts of the Drive, with the majority of the deaths or injuries having occurred within the last ten years.

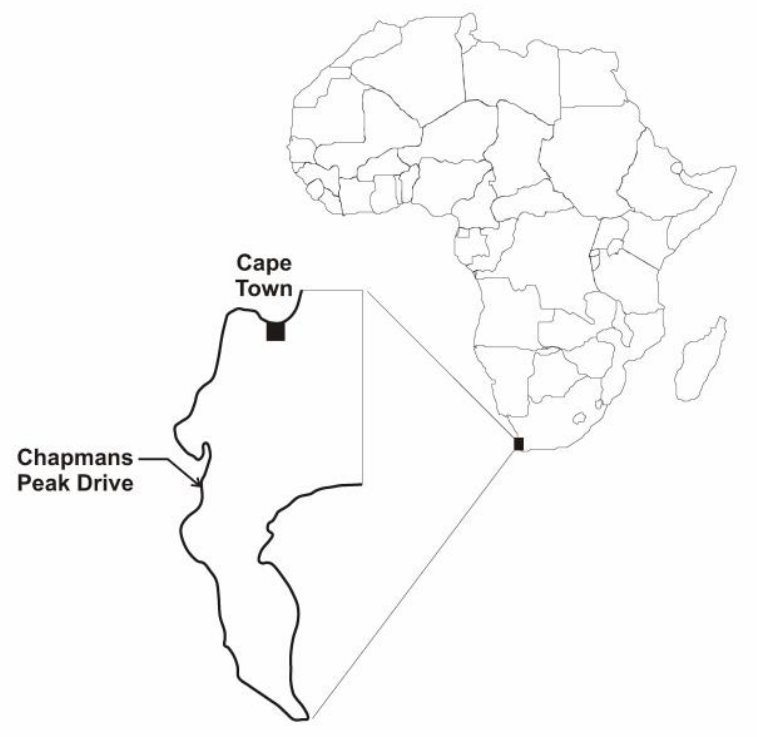

Figure 1 Location of Chapmans Peak Drive

The Drive was closed to traffic in early January 2000 because of a rockfall fatality. Subsequent to the death and, while the road was still closed, significant fires swept through the area, further de-stabilising the slopes. In an effort to rehabilitate the Drive, a rock scaling program was initiated shortly after the fires. It was soon realised, however, that the problems could not be overcome with scaling alone and this program was stopped. A design-build-finance-operate (DBFO) bid was subsequently put out to tender in order to mitigate the problems. This paper briefly describes the methodology used to understand the spatial distribution and 
magnitude of the rockfall problem along the Drive that was conducted as part of the design phase for the DBFO bid. The study provided key data required to develop preliminary designs and cost estimates, in order to mitigate the rockfall hazard. During the bidding process (early in 2001), Cape Town experienced its heaviest rains in approximately 40 years, which resulted in a record number of rockfalls and mud and debris slides onto the Drive.

The Drive has subsequently been rehabilitated and was opened to traffic again in 2004.

\section{Background information}

From a rockfall hazard perspective the Drive was divided into three distinct sections (Figure 2); a northern section (approximately $4 \mathrm{~km}$ long), a middle section (approximately $2.6 \mathrm{~km} \mathrm{long}$ ), and a southern section (approximately $3 \mathrm{~km}$ long). The north and south sections had few rockfall problems or potential rockfall hazards. The mid-section of the Drive hugs the mountain with a series of stepped shear cliffs up to $150 \mathrm{~m}$ high extending for $500 \mathrm{~m}$ above the road and included the locations of all major rockfall incidents. The midsection was considered to be the most hazardous section of the Drive and this paper deals only with this part of the Drive (Figure 2). The mid-section is referred to as the Drive for the remainder of this paper.

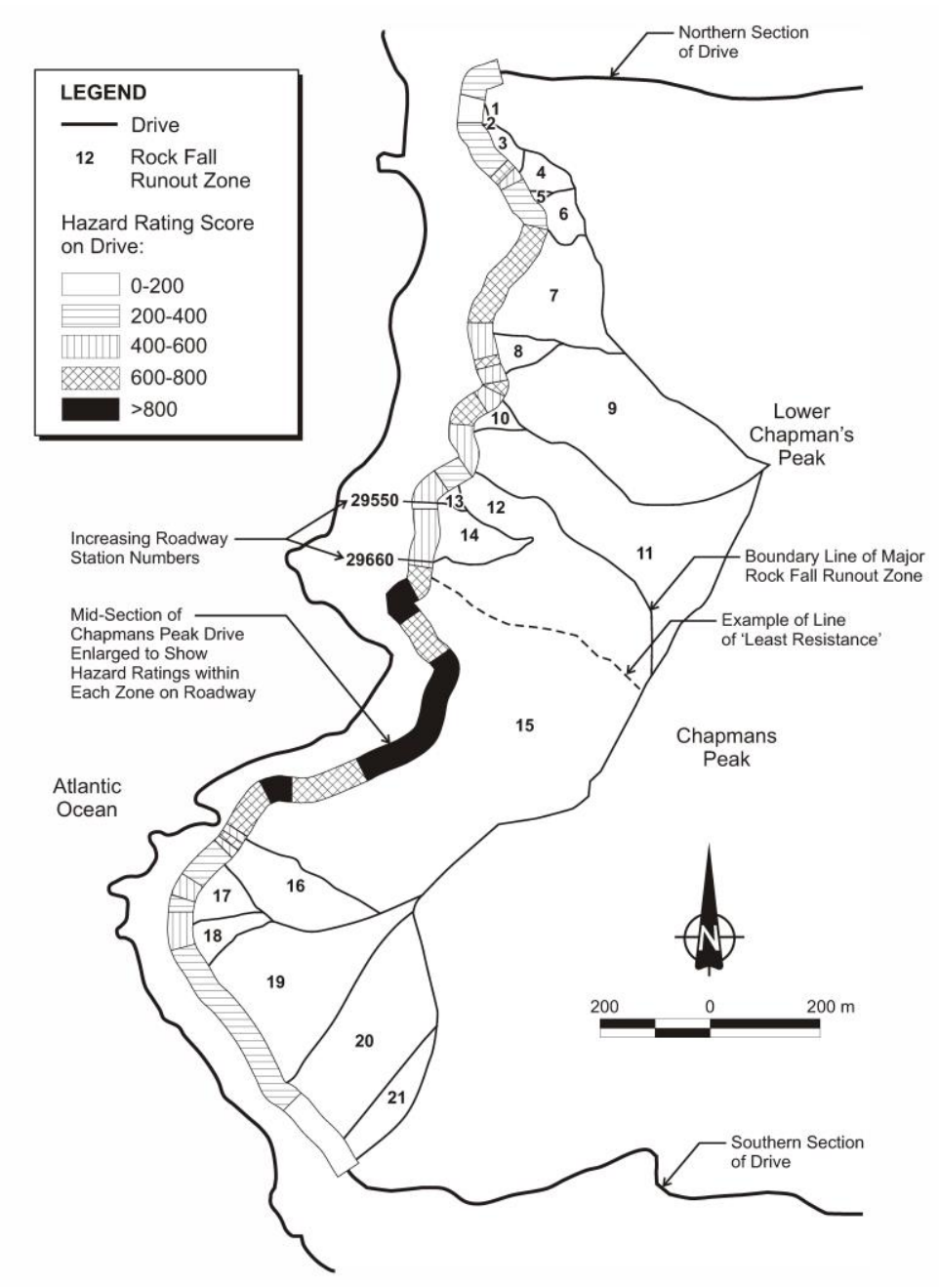

Figure 2 DEM of Chapmans Peak showing rockfall runout zones and hazard ratings for each zone

The mountainous terrain on the Drive is typically complex and extremely steep. The cliff bands are frequently near vertical to overhanging. Unstable blocks and wedges, some of which were car-sized or bigger, were observed to be present on most of the cliff bands providing one of the primary rockfall hazards. The cliff bands are typically interspersed with boulder strewn scree slopes with slope angles of between $35-55^{\circ}$. As a result of the fires, a significant percentage of the scree slopes had all binding vegetation 
obliterated. This exposed boulders of all sizes and shapes on the scree slopes, frequently perched at critical angles of repose, significantly increasing the potential hazard from these slope facets.

The approach used to assess the potential hazard and risk as a result of rockfall was multi-faceted and is briefly described below.

\section{Digital elevation model}

Before any mitigation measures could be considered, it was imperative that the spatial distribution and magnitude of the problem be understood. With this in mind, the initial step entailed setting up a digital elevation model (DEM) using Arc GIS. The DEM model was then used to delineate rockfall runout zones. A rockfall runout zone is defined as an area above the Drive where falling rocks are channelled into gullies and/or are contained between topographic features. Topographic features include crests of ridges and spurs and steep-sided gullies that extend down the mountainside, providing natural barriers that generally ensure that most falling rocks do not fall or roll into adjacent zones. A rockfall event within a particular rockfall runout zone may impact on the Drive or bounce over the road, but this will likely occur only between restricted lengths on the Drive of each defined zone. The predicted boundaries of major rockfall runout zones for the Drive are shown schematically in Figure 2.

Some zones comprise discrete chutes or gullies and rockfalling from anywhere within the zone will be channelled and will have similar fall pathways for a given block size. Other zones have similar topography (similar slope profiles without discrete gullies) throughout and rocks falling from similar height within a zone will probably have similar rockfall trajectories and energy distributions for a given block size.

To refine these zones and ensure that the zone boundaries were placed in the correct position, the Flow Path Tracing Tool in Arc GIS spatial analysts was used to determine typical descent paths or down slope movement within zones (example shown in Figure 2 - Zone 15 polygon line of least resistance). Besides confirming boundary positions, Flow Paths were assumed to simulate, to some degree, the three-dimensional (3D) affect or path of rocks as they bounce or roll down slope. Since the flow path and end points of these simulations correlated strongly with the observed end points of fallen boulders, it was assumed that the method was valid. Using this technique, 21 discrete zones were identified, and these were labelled sequentially from north to south, i.e. with increasing road station numbers from north to south (e.g. Zone 14, Figure 2). The station numbers at either end of discrete zones were subsequently used to indicate the location of these natural breaks and these zones formed the basis of all subsequent work.

\section{Rockfall hazard assessment}

In order to understand key factors influencing the rockfall hazard, it was necessary to undertake some form of hazard assessment that could be used to assess the relative hazard level at each rockfall runout zone identified using the DEM. This ensured that zones could be ranked in order of the potential danger they presented to the user.

The Oregon State Highway Division's Rockfall Hazard Rating System (O-RHRS) (Pierson et al., 1990) was initially considered for use. The system provides a method of making informed decisions on where and how to spend construction funds. An exponential scoring graph is used to represent the increase in hazard on the basis of nine categories; slope height, ditch effectiveness, average vehicle risk, percent of decision site distance, roadway width, geological character, quantity of rockfall/event, climate and rockfall history. The resulting total score provided a means of evaluating the relative risk of rockfall to the travelling public (Hoek, 2000).

For a number of reasons, which are discussed briefly below, it became necessary to adapt the RHRS system specifically for local conditions on Chapmans Peak Drive. It is assumed that the reader is familiar with/or will refer to the Oregon RHRS when reading this section, since space does not permit a more detailed treatment. Table 1, which provides an abbreviated version of the Chapmans Peak RHRS developed for the project, is not intended to be directly comparable to the Oregon classification scheme; rather it provided a rational method of determining key reasons why some zones were considered more hazardous than others, even though the zones were often in close proximity. 
Weighting factors were also applied to certain categories in the final analysis, because it is considered that some parameters contribute more to the overall hazard and therefore risk of fatalities than others. Slope height (increase in potential kinetic energy) and rockfall history categories were considered to be very important factors affecting individual zones. As a result, a factor of three was applied to the original O-RHRS scores assigned to these categories. Average vehicle risk and \% Decision Sight Distance (DSD) (defined in Hoek, 2000) distance were also considered to have an important influence on the probability of a fatality occurring and a factor of two (2) was applied in these cases. Geological character and block size or volume, while important, do not change significantly along the Drive, and the original O-RHRS scores were maintained in these cases, although the criteria had to be adjusted to fit field conditions.

Ditch width, road width and climate, on the other hand, were considered to be static and insensitive parameters on the Drive because they were essentially uniform throughout, and therefore a factor of 0.5 has been applied as a means of indicating that these categories are considered, but that they do not necessarily influence the vulnerability of zones in the same way as other parameters may.

Figure 2 also presents the final hazard rating on the Drive using the results from the adapted hazard rating system.

\subsection{Effective average slope height}

The highest effective slope heights encountered include Zone $9(411 \mathrm{~m})$, Zone 11 (356 m), and Zone 15 $(430 \mathrm{~m})$ respectively. The upper boundary lines of some Zones $(8,10,12,13,14,17$, and 18) do not reach the true crest of the mountain. The effective heights of these zones are the height of the upper rockfall runout zone boundary lines (delineated by topographic effects), rather than the actual height of the mountain. From observation and records it was known that most rockfalls initiated from the natural slopes above the road and not from rock cuts directly above the Drive, even though many of the cuts had heights greater than $30 \mathrm{~m}$. The entire mountain would, therefore, score maximum points in the O-RHRS and this parameter would be static and insensitive to observable height differences. Higher threshold slope height criteria were therefore established, and these and the relative scores (factor of three applied to the scores normally allocated per criteria) are shown in Table 1. These data were taken directly off the DEM.

Table 1 Abbreviated rockfall hazard rating system used on Chapmans Peak Drive

\begin{tabular}{|c|c|c|c|c|}
\hline \multirow[t]{2}{*}{ Category } & \multicolumn{4}{|l|}{ Criteria } \\
\hline & $2,3,6$ or $9 *$ & $5,9,18$, or $27^{*}$ & $14,27,54$, or $81 *$ & $41,81,54,243^{*}$ \\
\hline Slope height & 0-100 m [9] & $100-200 \mathrm{~m} \mathrm{[27]}$ & $200-300 \mathrm{~m} \mathrm{[81]}$ & $>300 \mathrm{~m} \mathrm{[243]}$ \\
\hline Ditch effectiveness & Good [6] & Moderate [18] & Limited [54] & None [162] \\
\hline AVR & $<25 \%[6]$ & $25-50 \%[18]$ & $50-150 \%[54]$ & $>150 \%$ [162] \\
\hline$\% \mathrm{DSD}$ & $>100 \%[6]$ & $100 \%[18]$ & $40-100 \%$ [54] & $<40 \%[162]$ \\
\hline Roadway width & $14 \mathrm{~m} \mathrm{[2]}$ & $11 \mathrm{~m} \mathrm{[5]}$ & $9 \mathrm{~m} \mathrm{[14]}$ & $6 \mathrm{~m}[41]$ \\
\hline Geologic character & $\begin{array}{l}\text { Limited source areas } \\
\text { for rockfall. Few } \\
\text { erosion features, } \\
\text { small difference in } \\
\text { erosion rate [3] }\end{array}$ & $\begin{array}{l}\text { Some source areas } \\
\text { for rockfall. } \\
\text { Occasional erosion } \\
\text { features, moderate } \\
\text { difference in erosion } \\
\text { rates [9] }\end{array}$ & $\begin{array}{l}\text { Many source areas } \\
\text { for rockfall. Many } \\
\text { erosion features, } \\
\text { large difference in } \\
\text { erosion rates [27] }\end{array}$ & $\begin{array}{l}\text { Major source areas } \\
\text { for rockfall. Major } \\
\text { erosion features, } \\
\text { extreme difference in } \\
\text { erosion rates [81] }\end{array}$ \\
\hline $\begin{array}{l}\text { Block size/quantity } \\
\text { of rockfall event }\end{array}$ & $\begin{array}{l}0.3 \text { m diam. blocks } \\
\text { max., or } 3 \text { cubic } \\
\text { meters per event [3] }\end{array}$ & $\begin{array}{l}0.6 \text { m diam. blocks } \\
\text { max., or } 5 \text { cubic } \\
\text { meters per event }[9]\end{array}$ & $\begin{array}{l}1 \mathrm{~m} \text { diam. blocks } \\
\text { max., or } 8 \text { cubic } \\
\text { meters per event [27] }\end{array}$ & $\begin{array}{l}2 \text { m diam. blocks } \\
\text { max., or } 10 \text { cubic } \\
\text { meters per event }[81]\end{array}$ \\
\hline $\begin{array}{l}\text { Climate and presence } \\
\text { of water on slope }\end{array}$ & $\begin{array}{l}\text { Low to moderate } \\
\text { precipitation, no } \\
\text { freezing periods, no } \\
\text { water on slope [2] }\end{array}$ & $\begin{array}{l}\text { Moderate } \\
\text { precipitation, no } \\
\text { freezing, intermittent } \\
\text { water on slope [5] }\end{array}$ & $\begin{array}{l}\text { High precipitation, } \\
\text { no freezing, frequent } \\
\text { water on slope [14] }\end{array}$ & $\begin{array}{l}\text { High precipitation, } \\
\text { no freezing, continual } \\
\text { water on slope }[41]\end{array}$ \\
\hline Rockfall history \# & $\begin{array}{l}\text { no damage or } \\
\text { rockfalls recorded [9] }\end{array}$ & only one layer [27] & $\begin{array}{l}\text { two layers intersect } \\
\text { [81] }\end{array}$ & $\begin{array}{l}\text { all three layers } \\
\text { intersect [243] }\end{array}$ \\
\hline
\end{tabular}

*Score used depends on factor used (see text); AVR - Average Vehicle Risk; \% DSD - Percent of Decision Sight Distance.

@ - Decision sight distance $=20 \mathrm{~m}$; \# - Based on intersecting layers of pre- and post-fire, and current rockfall events as determined by GIS analysis. 


\subsection{Ditch effectiveness}

The Drive hugged the mountain so closely at the time of survey that ditches were effectively non-existent along the Drive. All zones were therefore allocated the highest points possible for this criterion $0.5 \times 81$ points (Table 1 ).

\subsection{Average vehicle risk (AVR)}

Three hundred vehicles per hour was considered to be the average daily traffic number and was held constant for all zones. Slope length was considered to be the cumulative distance that a vehicle was exposed to hazards within a particular zone. A constant speed limit of $20 \mathrm{~km} / \mathrm{h}$ was used to calculate the AVR per zone. Posted speed limits were very slow because of poor line of sight distances.

Zones 1, 3, 7, 8, 10, 13, 14, 15, and 17 had the highest average vehicle risk. Rating points assigned for various class intervals are indicated in Table 1 (factor of two applied to the scores normally allocated per criteria).

\subsection{Percent of decision sight distance (\% DSD)}

According to the definition and published guidelines (Hoek, 2000), if the posted speed limit is $20 \mathrm{~km} / \mathrm{h}$ then a minimum decision sight distance of $160 \mathrm{~m}$ is required, where the \% DSD is defined as actual site distance divided by the decision site distance provided in guideline tables expressed as a percentage (Hoek, 2000). Extremely tight roadway curves and other obstructions such as rock cuts severely limited line of site distance on the Drive. As a result the low design decision site values normally recommended only occur along limited parts of the Drive.

In order to produce a result that was meaningful along the Drive, Arc GIS Spatial Analyst was used to determine actual line of sight distances along the Drive and the decision sight distance was taken as a constant $20 \mathrm{~m}$, since this was assumed to be the distance required for a vehicle to come to a complete stop when travelling at $20 \mathrm{~km} / \mathrm{h}$ or less. Where segments of road were identified with less than $100 \%$ DSD, it was then possible to identify curves or bends where less than $20 \mathrm{~m}$ of stopping distance was available for drivers to react.

The results of this work, while not directly comparable to other published work, provided a means of establishing the proportion or length of road within individual zones that had poor \% DSD and therefore added to the vulnerability within a zone. This analysis showed that Zones 1, 2, 5, 10, 13, and 17 had significant proportion of road length with \% DSD value that ranged between 19 and 39\%. Actual line of sight distance on some of the worst-case bends ranges from as little as 4-8 $\mathrm{m}$. The rating applied to the various classes or ranges of \% DSD are provided in Table 1 (factor of two applied to the scores normally allocated per criteria).

\subsection{Roadway width}

The Drive is mostly $6 \mathrm{~m}$ in width and therefore most of the Drive received the maximum high rating for this criterion $-0.5 \times 81$ points (Table 1 ).

\subsection{Geologic character}

The stability of rock cuts and natural rock slopes above the Drive are generally controlled by sub-horizontal bedding and sub-vertical joints. This lends itself to a blocky rock mass and toppling and parallel cliff retreat rather than classical planar- or wedge-type failures provide the key failure mechanisms. The geological conditions producing rockfall on the Drive are considered below.

Relatively soft, closely jointed and bedded, erodable, Graafwater formation siltstones and sandstones of the Table Mountain Group, are often found directly above the Drive and these are capped above by hard, widely jointed and bedded, more competent, durable quartzitic sandstones of the Peninsula formation. This difference in strength and erodability of the lower and upper layers of rocks has resulted in areas of the mountain above the Drive (Graafwater formation rocks) where the cliffs are undercut. This results in a source area of unstable slabs and blocks in the roofs of overhanging section of cliffs. The Drive is typically 
notched into the steep sides of Chapmans Peak along a sub-horizontal non-conformity, so that most of the Drive is underlain by very resistant, hard, poorly jointed Cape Granite Suite rocks.

The upper capping of resistant Peninsula sandstones has resulted in some spectacular cliffs. These cliffs are, however, subject to toppling and parallel retreat as blocks of variable dimensions work themselves loose and fall over time. The largest, and therefore most lethal, blocks observed lying on the Drive were quartzitic sandstone blocks and this provided evidence that the upper formation also provided a key source of rockfall. Observation also confirmed that the larger quartzitic sandstone blocks typically broke up less than the siltstone/sandstone blocks during their descent. It was also frequently observed that numerous blocks were mobilised (on scree slopes or on less steep cliff) as a consequence of a single initiating event.

Scree slopes with angles that vary from $35-55^{\circ}$ were frequently observed between cliff bands above the Drive. Boulders of all sizes were perched on the scree slopes and also provided a potential source of rockfall, particularly after the fires of 2000. Although relatively stable in dry conditions, these slopes are also susceptible to extreme erosion events and debris slides during heavy rainfall and this was exacerbated by the heavy rain of 2001.

On the basis of the above observations, descriptors (criteria) were developed that reflect the potential failure mechanisms within zones and the relative vulnerability of zones as a result of the geological conditions (Table 1).

Because of the extreme nature of the terrain, the assessment of conditions frequently required the use of oblique aerial photographs and, in some cases was also based on observation made while rappelling during the rock scaling program.

Zones that rated the worst in this category include Zones $7,8,10,11,15$, and 16 all with 81 points respectively. This was followed by Zones 3, 9, and 14 which were rated with 27 points respectively.

\subsection{Block size or quantity of rockfall per event}

Numerous blocks of between $0.5-2 \mathrm{~m}^{3}$ were frequently observed lying on the road during the bid phase investigation work (Figure 3). Occasionally blocks of up to $10 \mathrm{~m}^{3}$ were observed on the road. The largest individual blocks observed on the Drive were commonly identified as coming from the upper Peninsula formation quartzitic sandstones unit. The scaling program regularly revealed blocks of $8 \mathrm{~m}^{3}$ or more perched precariously on cliffs or on scree slopes. Smaller blocks from overhanging sections of cliff or siltstone/sandstone blocks from lower down the slopes probably have a higher frequency of occurrence, however, the common denominator for most source areas is the potential for very high falling velocities because of the vertical nature of the slope above the Drive.

Debris slides or slumps were numerous during the bid phase (up to $30 \mathrm{~m}^{3}$ in single events), but these were considered as outliers due to the heavy rain in early 2001.

Table 2 shows the criteria used and the related score per descriptive criterion. This table reflects observations made during the bid phase of work and information gleaned from rockfall inventories (see Section 4.9). The worst affected areas (highest rating) include Zones 4, 6, and 7-16.

\subsection{Climate and presence of water on slope}

Chapmans Peak as a whole has little protection from winter storms since it faces virtually head-on into the prevailing NW winds that bring the cold fronts. Individual zones probably do not have significantly differing weather conditions. It is considered that the Drive generally fits into the second category (Table 1). That is moderate to high precipitation in winter due to cold fronts, resulting in intermittent water on the slopes without freeze and thaw conditions. This results in a score of $0.5 \times 9$ points for each zone. While this may not provide any sensitivity to compare zones, this category was included in this hazard rating since it provides a reminder that this is one of the key factors that can influence or trigger rockfall events. 


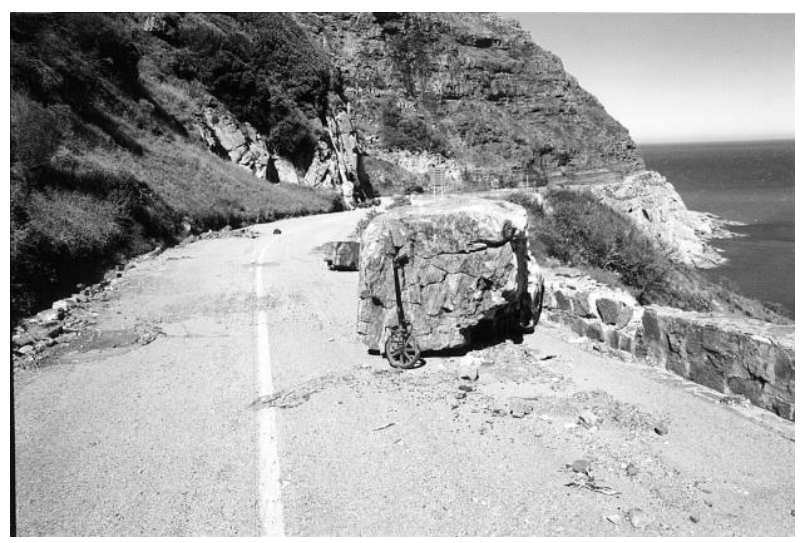

Figure 3 A 2-3 $\mathrm{m}^{3}$ peninsula sandstone block at rest on the Drive

\subsection{Rockfall history}

This information has been gleaned from, albeit poor, records of known rockfall events on this part of the Drive. This provided discrete time capsules of information on the volume, frequency, and potential spatial distribution of future rockfall events. It also provides a means of comparing the score given to other criteria (e.g. geology and block size), to see if there was some correlation between the rockfall history and the variability assigned to these factors that may influence the frequency of events.

Three time frames or sets of records of damage and rockfall events were taken into account, namely:

- Pre-fire damage (to the road surface) and rockfalls recorded prior to the fire that occurred in January 2000 (volumes and block sizes not known).

- Post-fire damage, i.e. records after the fires and after the rock scaling program (no volumes were available).

- Recent rockfalls recorded after the road was cleared of all rock scaling debris and includes material that landed on the road during the recent heavy winter rains (July to September 2001).

Arc GIS was then used to determine sectors or lengths on the Drive where the rockfall records from all three periods described above overlapped in a spatial sense, providing some indication of the frequency of events. The same was done to determine localities where two periods overlapped and where rockfall was recorded only during one of the periods mentioned above. Table 1 presents the descriptors or criterion applicable to the various scores (factor of three applied to conventional scores). A range of scores was recorded within individual zones. This reflected the fact that certain parts of the road may be more vulnerable, but the source of rockfall is still within a discrete zone.

From this work it was concluded that Zones 3, 6, 7, 8, 9, 10, 15, and 16 had the worst accumulative rockfall history over significant length of road within these zones. Some judgment has to be applied when reviewing these results, since the record of rockfalls during the scaling operation is indicative of what is possible, but it is also probable that where rock scaling was undertaken the hazard level was reduced by some factor.

\subsection{Overall hazard rating for zones}

Arc GIS Spatial Analyst was used to determine the overall rating along the Drive and these results are summarised in Figure 2. Given the fact that the ratings for individual categories can vary within zone boundaries, it is evident that a range of cumulative or overall ratings can apply within individual zones.

The results of this work show that Zones 7, 9, 10, 15, and 16 had ratings that are consistently higher than 600 and are often $>800$ for significant lengths within these zones. These zones were therefore considered to have the highest level of vulnerability to rockfall when all the factors were considered and would likely require major remedial measues to reduce the risk of fatalities. Zones 2, 3, 4, 11, 13, 14, 16, and 17 have sections of road that have overall ratings that fall in the 400 to 600 category. Other zones (Zones 1, 5, 12, and 18 to 21 
respectively) had, comparatively, lower ratings and therefore reduced levels of vulnerability, and less stringent remedial measures could be considered in these cases.

These ratings can only provide an indication of the inherent hazard and risk (and associated consequences) and cannot be viewed in isolation from the results of more quantitative work required to design actual remedial measures, but the results certainly identified key zones and helped elucidate the reasons for their significance.

\section{$5 \quad$ Rockfall trajectory analyses}

\subsection{Introduction}

The path that falling rocks can potentially take, the associated kinetic energy, and the bounce heights and velocities are very important factors that influence the risk to road users, particularly when designing mitigation measures. In order to understand the potential magnitude of the rockfall problem, rockfall trajectory analyses were undertaken on all zones shown in Figure 2 using a computer simulation programme called Rocfall produced by Rocscience Geomechanics Software and Research, Toronto, Canada.

\subsection{Method of assessment}

It was assumed for the analyses that rocks are dislodged from the highest possible points within a particular zone and from a number of other lower points. Typical cross-sections were generated along potential GIS 3D simulated trajectory paths, i.e. one for each zone and two in Zone 15, since this zone covers the largest surface area on the mountain (Figures 2 and 4). Cross-sections generated from the DEM provided the starting point. The DEM smoothed flow path simulated profiles did not always reflect the reality of this complex terrain. Due to lack of detailed survey data, a correction was achieved by using the DEM smoothed profiles as base sections (since the elevation difference between the road and the crest of zones were correct, as were the location of the road and the crest of the mountain). Then, with the use of oblique aerial photographs and field checking, cross-sections were adjusted to include visible cliff bands and scree slopes (or slopes vertices in Rocfall). This process, which ultimately resulted in $\mathrm{x}-\mathrm{y}$ coordinate pairs, required for input into Rocfall, cannot reproduce exact surface profiles but it is contended that the results were a reasonable approximation, given that, with Rocfall, it is possible to build in some variance to account for potential profile undulations.

In order to keep the number of iterations to a reasonable number, analyses were restricted by simulating rockfall for a block of $1 \mathrm{~m}^{3}$ only. This was a contentious point, but it was the design block designated by the client for the bid phase work. For the simulation, two scenarios were examined; 1) potential worst case impact energies on the road for individual zones, for the design block size, and 2) potential impact energies on strategically placed (some field checking done) barriers for individual zones, for the same block size.

These data provided a convenient means to compare zones based on impact energies and bounce heights and to compare the feasibility or effectiveness of barriers (capacity and height requirements).

Figure 4 shows one of the profiles generated for Zone 15 and the simulated rockfall trajectories. Table 2 summarises data for some of the worst case zones in order to provide an indication of the magnitude of some of the impact energies possible.

\subsection{Results of trajectory analyses}

It should also be noted that a minimum of 50 rocks were seeded (in the simulation) from a number of likely event points on the cross-sections in order to determine variability in trajectory, kinetic energy levels, and velocities. Table 4 provides a summary of some of these results. 


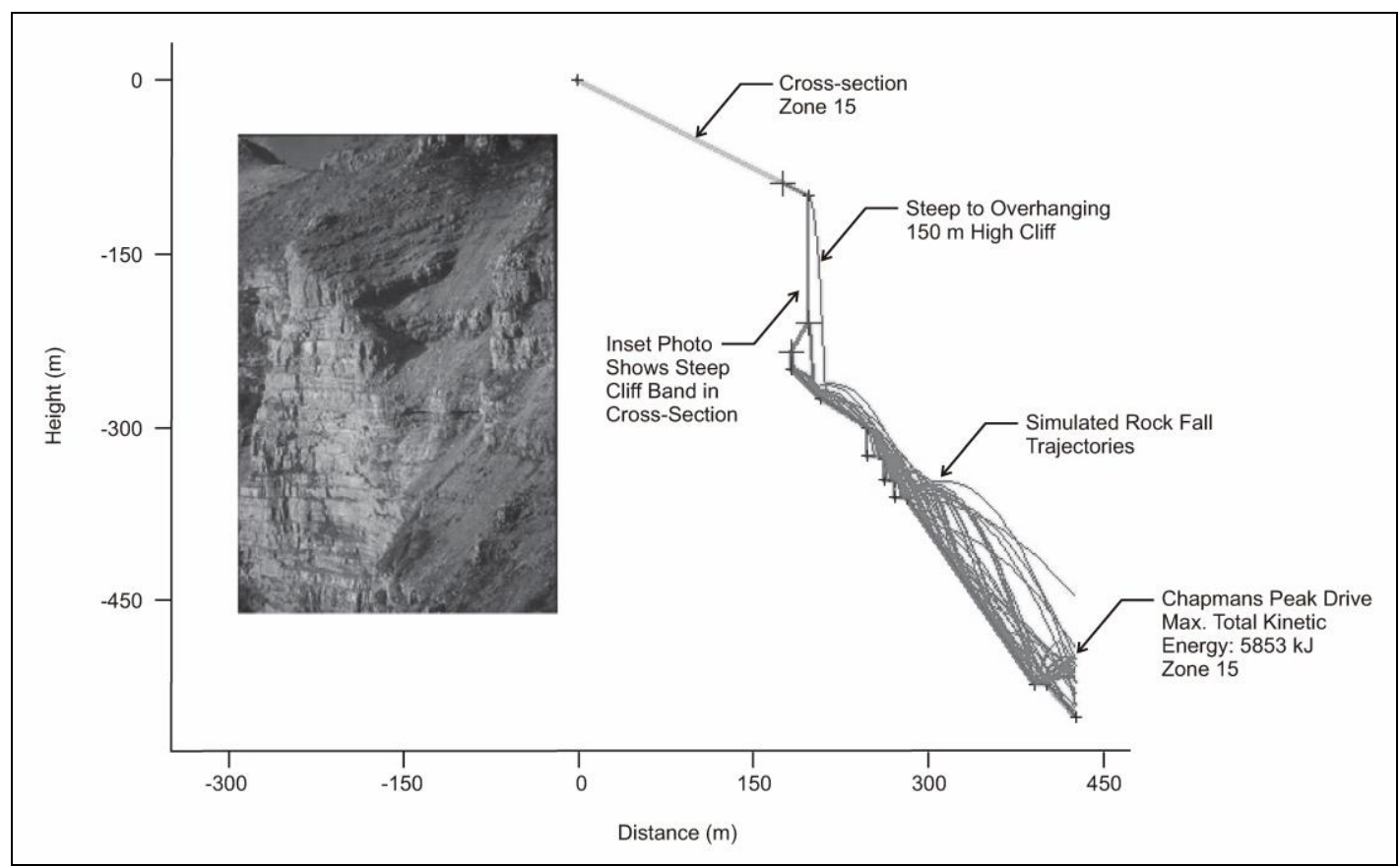

Figure 4 Zone 15 rockfall simulation trajectory paths (insert photograph shows the upper cliff band evident in the cross-section)

Factors such as the geometry of the slope profile and the properties of the various slope segments can influence the results. For this project, values for slope friction angles and coefficients of normal and tangential restitution were typically selected as default values for a selection of surface types (e.g. bare rock, talus, etc.) It is possible, however, given enough field data to back analyse developed rockfall trajectory models in order to provide calibrated values for slope friction angles and coefficients of normal and tangential restitution. This typically requires knowledge of end point location and size of fallen boulders. Recent Australian experience on another job showed that it was possible to generate very similar fallen rock/boulder distribution end points observed on site. The results of the modelling for the Australian job using the calibrated models provided a high level of confidence that the end points of falling rocks, the potential energy distribution, and bounce heights could be relied on to make informed design decisions.

For Chapmans Peak, the nature of the terrain made it difficult to calibrate models for individual zones. However, observations during the scaling program undertaken (discussed in Section 1) provided some opportunity to ascertain that the results were reasonable, and these are discussed briefly below.

Table 2 Example of summary results of rockfall analyses - Chapmans Peak Drive

\begin{tabular}{|c|c|c|c|c|c|c|c|c|}
\hline \multirow{2}{*}{$\begin{array}{l}\text { Zone } \\
\text { Number }\end{array}$} & \multirow{2}{*}{$\begin{array}{l}\text { Zone } \\
\text { Length }\end{array}$} & \multirow{2}{*}{$\begin{array}{l}\text { Maximum } \\
\text { Total Kinetic } \\
\text { Energy on } \\
\text { Road }\end{array}$} & \multicolumn{3}{|c|}{ Rock Bounce Height at Barrier } & \multicolumn{3}{|c|}{$\begin{array}{c}\text { Total Kinetic Energy at } \\
\text { Barrier }\end{array}$} \\
\hline & & & Min. & Max. & Mean & Min. & Max. & Mean \\
\hline & (m) & $(\mathrm{kJ})$ & $(\mathrm{m})$ & (m) & $(\mathrm{m})$ & $(\mathrm{kJ})$ & $(\mathrm{kJ})$ & $(\mathrm{kJ})$ \\
\hline 2 & 10 & 705 & 0 & 1.95 & 0.4 & 103 & 324 & 206 \\
\hline 3 & 120 & 823 & 0 & 3.21 & 0.26 & 4 & 724 & 286 \\
\hline 7 & 220 & 1974 & 0 & 3.04 & 0.55 & 236 & 1210 & 518 \\
\hline 8 & 90 & 4623 & 0.12 & 52.41 & 13.85 & 566 & 4370 & 2690 \\
\hline 10 & 110 & 1243 & 0 & 7.62 & 0.68 & 45 & 776 & 282 \\
\hline 11 & 60 & 5005 & 0 & 43.8 & 12.1 & 298 & 5250 & 1510 \\
\hline 12 & 20 & 5252 & 0 & 51.3 & 14.2 & 931 & 4840 & 2720 \\
\hline 14 & 110 & 3726 & 0.28 & 22.7 & 6.6 & 360 & 4470 & 1370 \\
\hline 15 & - & 5853 & 0.92 & 46.57 & 14.47 & 1090 & 4550 & 2670 \\
\hline 16 & 50 & 4985 & 0.13 & 97.69 & 53.2 & 265 & 4910 & 2480 \\
\hline
\end{tabular}


The bounce heights in some case appeared to be extreme. This was however, more a function of the verticality of the topography in certain zones. In some cases shear cliffs band $(>50 \mathrm{~m})$ were present directly above the road and bounce heights were more indicative of falling rock bouncing over the top of cliff band and going right over the top of the Drive than a true bounce height above a barrier.

\subsubsection{Maximum kinetic energy on the road}

Zone 9 had possible kinetic energies that range between $0-700 \mathrm{~kJ}$. Zones 1, 2, 3, and 5 have possible kinetic energies that range between 700-1000 kJ, assuming falls from the upper reaches of these slopes. Zones 7, 10, $18,19,20$, and 21, on the other hand, have a possible range of 1000-2000 kJ. Zones 4, 6, 13, and 17 have a possible range of 2000-3000 kJ. Zones $8,11,12,14,15$, and 16, however, have the highest possible range with energy values falling between 3000 and $6000 \mathrm{~kJ}$ (Table 2).

In conjunction with the hazard rating values, the assessed potential kinetic energy levels within zones provided a powerful means of understanding all the major factors that can influence the risk and the potential consequence resulting from a rockfall event within a zone. This provided a starting point for conceptualising possible remedial solutions for the different zones.

\subsubsection{Energy at theoretical barriers (catch fences)}

The second phase of this study involved inserting theoretical barriers on cross-section as a method of comparing the possible reduction in impact energies per zone (as a result of a reduction in energy with an elevated location of a barrier above the road) with those anticipated on the actual Drive.

The Rocfall program has the ability to insert theoretical barriers at various positions on slope profiles and from this determine a range of possible impact energies, bounce heights, and trajectories for blocks of a given size $\left(1 \mathrm{~m}^{3}\right.$ - designated design block) per zones compared to that possible on the road. These data also provided basic information required to design catch fences in zones where these were considered to be a feasible alternative. In some cases it was apparent that barrier would not work at all, but the data was recorded anyway.

Table 2 provides examples of the minimum, maximum and mean values of bounce height and kinetic energy on barriers for selected zones.

Space does not permit a detailed treatment of these results; suffice to say that Zones $8,11,12,14,15$, and 16 still had impact energies that exceed $3000 \mathrm{~kJ}$ and mean bounce heights of greater than $8 \mathrm{~m}$, which exceeded the upper limits of certified commercially available rockfall catch fences at that time.

Finally, an anomaly is evident in Table 2 that needs clarification. For Zones 11 and 14, the maximum energy on the road is less than the maximum energy recorded on the theoretical barriers. This is simply a function of the 'theoretical barrier tool' in the Rocfall program, which records the energy of all rocks that move past an inserted barrier, irrespective of the trajectory and includes rocks that would ultimately bounce over the road. This can be different from the maximum kinetic energy recorded on the road alone, since these data are taken from the total kinetic energy envelope in Rocfall for falls that land on the road only and the results do not include rocks that bounce over the road.

\section{Risk evaluation}

The preceding sections dealt with the methods used to identify rockfall runout zones and the factors that affect the hazard level along the Drive as a result of rockfall. All of these factors need to be considered when trying to quantify the risk associated with individual zones.

\subsection{Event tree analysis and the resultant risk}

Probability analyses were undertaken for each zone and the risk or fatalities due to rockfalls are summarised for selected zones in Figure 5. Space does not permit a detailed explanation of the event tree risk method used; suffice to say that it was very similar to the method described by Hoek (2000). 


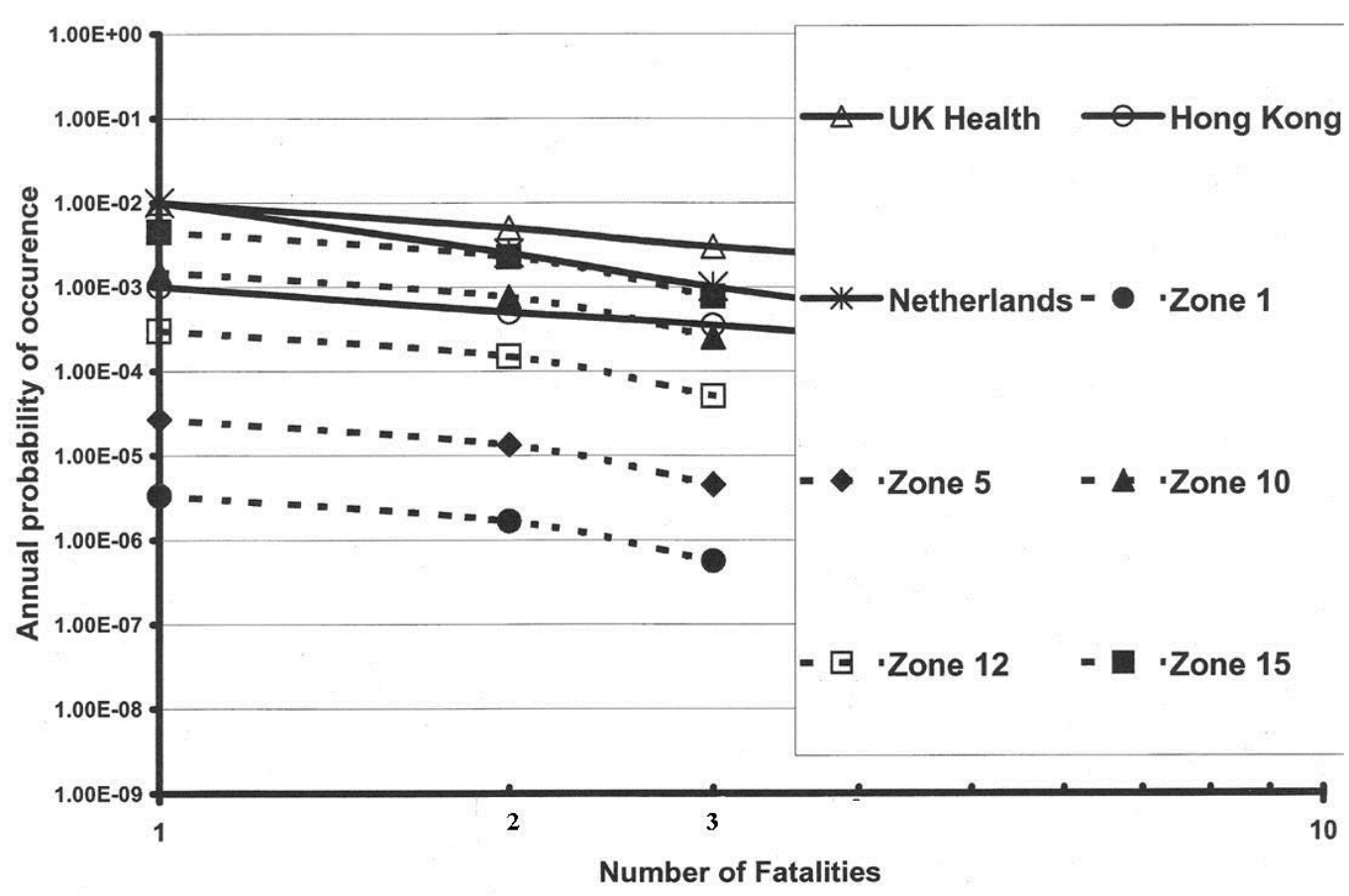

Figure 5 Comparison between risks of fatalities due to rockfall for zones with published acceptable risk criteria

\subsection{Published guidelines for tolerable risk}

Figure 5 shows curves of annual probability of occurrence with increasing number of fatalities. The bold lines summarise published and proposed guidelines for tolerable risk in Canada and Hong Kong (shown as Hong Kong line in Figure 5), Netherlands and UK, respectively. Event tree analyses were undertaken for all zones on the Drive. For clarity, the results from only a select number of zones are shown in Figure 5.

According to Hoek (2000), consensus is now developing in Canada and other developed nations that the annual probability of 1 in $10,000(1.00 \mathrm{E}-4$ on the figure) defines the boundary between voluntary risk (restricted to the general public) and involuntary risk (acceptable for the public). From the event tree analysis it turns out that Zones 7, 8, 10, 11, 14, 15, and 16 fell above the Canada and Hong Kong risk lines and these zones were considered to have an unacceptable risk profile. Other zones generally fell below the threshold risk levels, i.e. had marginal to low risk profile (Schlotfeldt, 2007).

\section{Conclusion}

Potential exists for a $1.2 \mathrm{~km}$ long tunnel route to divert the traffic away from the most dangerous part of the Drive. This solution, which was recommended to the client, would have provided a relatively low risk solution compared to the most dangerous zones.

However, the client wanted to retain the original alignment and aesthetics on the Drive. The result of the study outlined above provided a powerful starting point to developing conceptualised remedial measures, producing preliminary designs, and developing schedule of quantities and cost estimates for individual zones on the Drive. These data and designs formed the core of the design, build, finance, operate bid.

Solutions range from reinforced concrete and fill covered roadway sections, to half tunnels in rock, to multiple deflector rockfall catch fences (acting to deflect and channel falling rocks and to reduce energy), to a single catch fences (with a range of capacities and heights), to single cantilevered catch fence (anchored on vertical rock cuts above the Drive). For existing rock cuts, scaling and the installation of rockfall protection netting were proposed, depending on the hazard level present. Selective rock scaling was also factored into the bid in order to make certain areas safer for construction workers. 
In the end the DBFO consortium that the author worked for did not win the work, but the results formed a valuable contribution to the knowledge of the mountain.

\section{References}

Hoek, E. (2000) Rock Engineering, Chapter 9, pp. 115-136. Available on www.rocscience.com.

Pierson, L.A., Davis, S.A. and van Vickle, R. (1990) Rockfall Hazard Rating System Implementation Manual. Federal Highway Administration (FHWA) Report FHWA-OR-EG-90-01. FHWA, U.S. Department of Transportation.

Schlotfeldt, P. (2007) Rockfall hazard assessment of Chapmans Peak Drive, Cape Town, South Africa. Rock Mechanics: Meeting Society's Challenges and Demands, Eberhard, E. Stead, D. and Morrison, T. (editors), Taylor Francis Group, London, ISBN 978-0-415-44401-9, pp. 887-894. 